\title{
LIDAR SPRECTROSCOPY INSTRUMENT (LISSI): AN INFRASTRUCTURE FACILITY FOR CHEMICAL AEROSOL PROFILING AT THE UNIVERSITY OF HERTFORDSHIRE
}

\author{
Matthias Tesche ${ }^{1, *}$, Boyan Tatarov ${ }^{1}$, Youngmin Noh $^{2}$ and Detlef Müller ${ }^{1,2}$ \\ ${ }^{1}$ University of Hertfordshire, Hatfield, United Kingdom, *m.tesche@herts.ac.uk \\ ${ }^{2}$ Gwangju Institute of Science and Technology, Gwangju, South Korea
}

\section{ABSTRACT}

The lidar development at the University of Hertfordshire explores the feasibility of using Raman backscattering for chemical aerosol profiling. This paper provides an overview of the new facility. A high-power Nd:YAG/OPO setup is used to excite Raman backscattering at a wide range of wavelengths. The receiver combines a spectrometer with a 32-channel detector or an ICCD camera to resolve Raman signals of various chemical compounds.

The new facility will open new avenues for chemical profiling of aerosol pollution from measurements of Raman scattering by selected chemical compounds, provide data that allow to close the gap between optical and microphysical aerosol profiling with lidar and enables connecting lidar measurements to parameters used in atmospheric modelling.

\section{INTRODUCTION}

Conventional Raman or high spectral resolution lidar is used for deriving profiles of aerosol optical properties and, if proper input data are provided, retrieving aerosol microphysical properties through inversion techniques. The lidar development at the University of Hertfordshire (UH) is centred on exploring the feasibility of using Raman backscatter of various target species to obtain mass concentration profiles of selected chemical compounds. This marks the logical next step in aerosol profiling with lidar and will allow for defining aerosol types according to their chemical composition rather than optical properties. Ultimately, this will unify the treatment of aerosol types in lidar remote sensing with that of in-situ measurements and atmospheric modelling. The feasibility of the underlying methodology has been proven for measurements of Raman backscattering at silicone dioxide molecules within Asian dust layers [1, 2, 3].

\section{OBJECTIVES}

The lidar spectroscopy instrument (LiSsI) will enable profiling of trace gases, chemical components in particles, and bio-aerosols in atmospheric aerosol pollution through the combination of different nonlinear spectroscopy techniques (photoluminescence, fluorescence, Raman and coherent anti-Stokes Raman spectroscopy) in a single measurement platform. The work at UH includes (1) the development of an end-to-end simulator that allows us to model the processes of inelastic photoluminescence and Raman scattering by aerosol particles and gases in the context of lidar remote sensing, (2) the identification of the luminescence and Raman scattering characteristics for a set of key aerosol types and gases (of natural and anthropogenic origin) by means of laboratory experiments, (3) test measurements and case studies as a proof of concept of the technique under laboratory conditions, and (4) the characterisation and development of a mobile prototype inelastic lidar spectrometer receiver for field deployment at established lidar sites.

\section{LABORATORY SETUP}

Figure 1 presents a sketch of the setup of the LiSsI facility. The main components are a high power Nd:YAG laser (Continuum Powerlite Furie LD), an Optical Parametric Oscillator (Horizon OPO), a motorised beam combiner, a multiwavelength depolarisation Raman lidar receiver, a Horiba $1250 \mathrm{M}$ spectrometer that can be used with an intensified CCD camera (ICCD, Princeton Instruments PI-MAX4 1024i-HBf) or a 32-channel Licel PMT (32PMT), an Olympus BX51TRF-6 Raman/flourescence microscope, and several custom-made gas chambers.

An overview of the properties of the transmitter is provided in Table 1 . The combination of a highpower Nd:YAG laser and an Optical Parametric Os- 


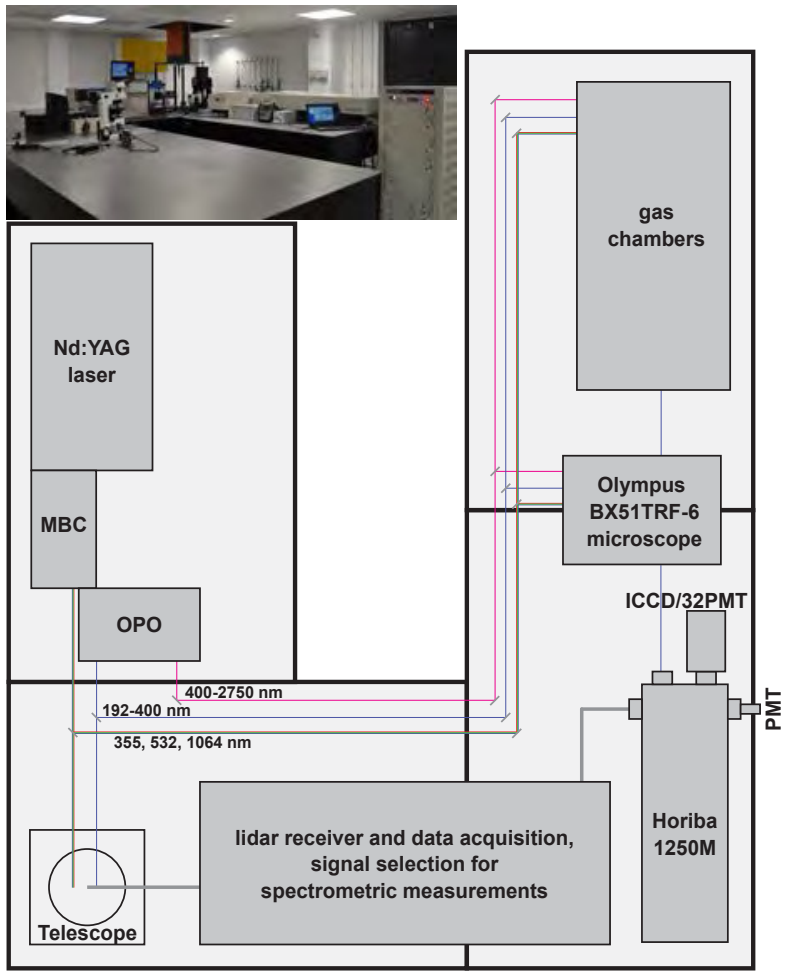

Figure 1: Sketch of the laboratory setup including a high-power Nd:YAG laser, a motorised beam combiner $(\mathrm{MBC})$, an Optical Parametric Oscillator (OPO), an advanced lidar receiver, a spectrometer, an intensified CCD camera (ICCD), a 32-channel Licel PMT (32PMT), a Raman/flourescence microscope, and several gas chambers.

cillator allows for exciting Raman backscatter for a wide range of excitation wavelengths. The novel lidar receiver setup has been designed and simulated using ZEMAX and will combine the spectral resolution of spectrometers with a 32-channel detector to resolve Raman signals of a variety of chemical compounds. An overview of the configuration and properties of the receiver and data acquisition is provided in Table 2. Aerosol chambers will enable measurements of a range of chemical species to test the methodology for known compounds and to assess the respective detection limit with respect to applied laser power and resolvable particle concentrations. A Raman microscope will be used to measure the Raman scattering cross-sections of the selected target species-information that is needed to transform the detected signals into mass concentrations.
Table 1: Properties of the transmitter.

\begin{tabular}{|c|c|}
\hline \multicolumn{2}{|c|}{ Continuum Powerlite Furie LD } \\
\hline Laser type & Nd:YAG, injection seeded \\
\hline Wavelength and & 7500 mJ @1064nm \\
\hline pulse energy & $5000 \mathrm{~mJ} @ 532$ nm nm \\
\hline & 2500 mJ @355 nm \\
\hline Beam divergence & $0.5 \mathrm{mrad}, 0.1 \mathrm{mrad}$ after \\
\hline & 5-fold beam expansion \\
\hline Repetition rate & $10 \mathrm{~Hz}$ \\
\hline Linewidth & $<0.003 \mathrm{~cm}^{-1}$ \\
\hline Pulse duration & $<15 \mathrm{~ns}$ \\
\hline \multicolumn{2}{|c|}{ Horizon Optical Parametric Oscillator } \\
\hline Pumping wavelength & $355 \mathrm{~nm}$ \\
\hline Wavelength and & from 192 to $2750 \mathrm{~nm}$ \\
\hline pulse energy & scanning step $0.01 \mathrm{~nm}$ \\
\hline & $120 \mathrm{~mJ} @ 400 \mathrm{~nm}$ \\
\hline & 25 mJ@300nm \\
\hline Beam divergence & $<2 \operatorname{mrad}$ (both axes) \\
\hline Repetition rate & $10 \mathrm{~Hz}$ \\
\hline Linewidth & $2-6 \mathrm{~cm}^{-1}$, injection seeded \\
\hline Pulse duration & $<15 \mathrm{~ns}$ \\
\hline
\end{tabular}

The aim of the facility is to carry out precise inelastic spectroscopy experiments that target measurements of photoluminescence, fluorescence, and Raman spectra of aerosol and gas samples. These measurements will include the identification of spectra, absolute values of fluorescence, and Raman cross-sections that are currently poorly known or unknown.

\section{APPLICATIONS IN LIDAR AND SPEC- TROSCOPY}

The LiSsI facility has been designed to allow for comprehensive laboratory experiments as well as for atmospheric observations. The laser beam can be released into the atmosphere through a hatch in the roof of the laboratory. The backscattered light is collected with a 14-inch Schmidt-Cassegrain telescope and guided to the different components of the receiver (Table 2). Depending on the setup of the experiment, LiSsI can be used as multiwavelength elastic backscatter lidar for measurements of aerosols and temperature from the troposphere to the mesosphere, as multi-channel spectroscopic Raman lidar (using Stokes and anti-Stokes, rotational, and rotational-vibrational Raman scattering), multi-channel spectroscopic photoluminescence/fluorescence lidar, high spectral resolution li- 
Table 2: Properties of the receiver and data acquisition system.

\begin{tabular}{|c|c|}
\hline \multicolumn{2}{|r|}{ Schmidt-Cassegrain telescope } \\
\hline Focal length & $3910 \mathrm{~mm}(14$ inch $)$ \\
\hline Field of view & $0.5-4.0 \mathrm{mrad}$ (variable) \\
\hline \multicolumn{2}{|r|}{ HORIBA 1250M Research Spectrometer } \\
\hline Focal length & $1.25 \mathrm{~m}$ \\
\hline Aperture & $\mathrm{F} / 9$ \\
\hline Spectral range & $0-1500 \mathrm{~nm}$ mechanical range $(1200 \mathrm{~g} / \mathrm{mm}$ grating $)$ \\
\hline Grating size & $110 \mathrm{~mm} \times 110 \mathrm{~mm}$ \\
\hline Dispersion@500nm & $0.65 \mathrm{~nm} / \mathrm{mm}$ \\
\hline Accuracy & $\pm 0.15 \mathrm{~nm}$ \\
\hline Repeatability & $\pm 0.005 \mathrm{~nm}$ \\
\hline Gratings & $2400 \mathrm{~g} / \mathrm{mm}$ blaze $250 \mathrm{~nm}$, max resolution $0.003 \mathrm{~nm}$ \\
\hline and resolutions & $1800 \mathrm{~g} / \mathrm{mm}$ blaze $400 \mathrm{~nm}$, max resolution $0.004 \mathrm{~nm}$ \\
\hline @313.183 nm & $1200 \mathrm{~g} / \mathrm{mm}$ blaze $330 \mathrm{~nm}$, max resolution $0.006 \mathrm{~nm}$ \\
\hline & $600 \mathrm{~g} / \mathrm{mm}$ blaze $500 \mathrm{~nm}$, max resolution $0.012 \mathrm{~nm}$ \\
\hline \multicolumn{2}{|r|}{ Detection } \\
\hline Mie and Rayleigh & $355 \mathrm{~nm}$, PMT HV-R9880U-20, bandwidth $1.3 \mathrm{~nm}$ \\
\hline scattering & $532 \mathrm{~nm}$, PMT HV-R9880U-20, bandwidth $1.3 \mathrm{~nm}$ \\
\hline & $1064 \mathrm{~nm}$, APD InGaAs50, bandwidth $4 \mathrm{~nm}$ \\
\hline Spectroscopic 1 & Hamamatsu H7260-20, $0.8 \mathrm{~mm} \times 7 \mathrm{~mm} \times 32$ anodes \\
\hline Licel SP32-20 & spectral response $300-920 \mathrm{~nm}$ \\
\hline Spectroscopic 2 & $1024 \times 1024$ imaging pixels; $12.8 \mu \mathrm{m} \times 12.8 \mu \mathrm{m}$ pixels \\
\hline Princeton Instruments & Gen III filmless intensifier \\
\hline PI-MAX4 & Sensitive range $290-710 \mathrm{~nm}$ \\
\hline ICCD camera & $\mathrm{QE}>20 \%$ in range $355-700 \mathrm{~nm}$; $\mathrm{QE}>40 \%$ in range $410-640 \mathrm{~nm}$ \\
\hline \multicolumn{2}{|r|}{ Data acquisition system } \\
\hline $\begin{array}{l}\text { Mie and Rayleigh } \\
\text { scattering }\end{array}$ & $\begin{array}{l}\text { Licel transient recorders, } 16 \mathrm{bit}, 20 \mathrm{MHz} \text { A/D converters and photon-counters } \\
\text { maximum count rate } 250 \mathrm{MHz} \text {, variable range resolution }\end{array}$ \\
\hline Multi-anode PMT & Single-photon counting system, maximum count rate $100 \mathrm{MHz}, 50 \mathrm{~ns}$ resolution \\
\hline ICCD & Digitization 16 bit, $32 \mathrm{MHz}$, minimum gate width $2 \mathrm{~ns}$ \\
\hline
\end{tabular}

dar (HSRL), polarization lidar, or infrared absorption and differential absorption lidar (DIAL).

In addition, LiSsI opens possibilities for a wide range of applications in spectroscopy: general spectroscopy (attenuation, transmission, and reflectance spectroscopy), high-spectral resolution spectroscopy, Stokes and anti-Stokes Raman spectroscopy of gas and solid material including applications involving a microscope, fluorescence spectroscopy of gas and solid material including microscope applications, laser-induced breakdown spectroscopy, coherent-anti-Stokes Raman spectroscopy, time-resolved spectroscopy, infrared gas analysis and materials processing.

\section{FIRST RESULTS}

The LiSsI laser has been installed in September 2017. Figure 2 shows one of the first measure-

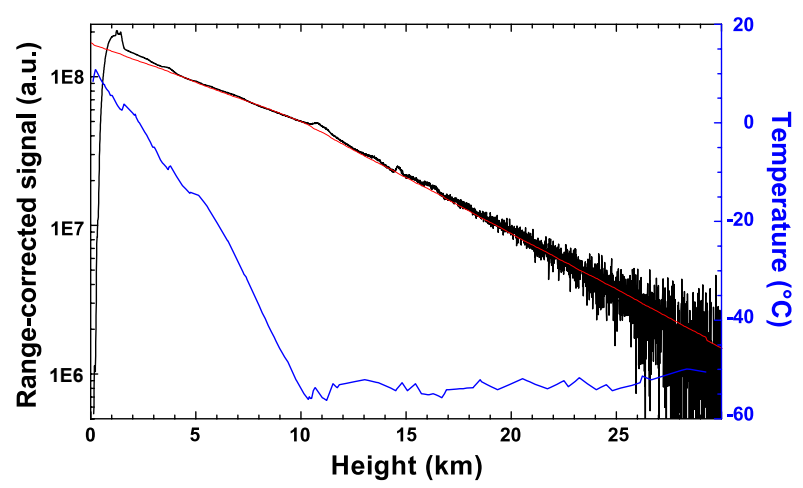

Figure 2: First measurement at $532 \mathrm{~nm}$ on 22 September 2017 (black) together with a molecular (red) and a temperature (blue) profile from a sounding launched at Nottingham at 0000 UTC on 22 September 2017.

ments performed between 1026 and 1330 UTC on 22 September 2017 using only a 532-nm elastic channel and a laser power of about $30 \mathrm{~mJ}$. The ana$\log$ counting signal is shown in the figure. Despite the low laser power, a rather small telescope and 


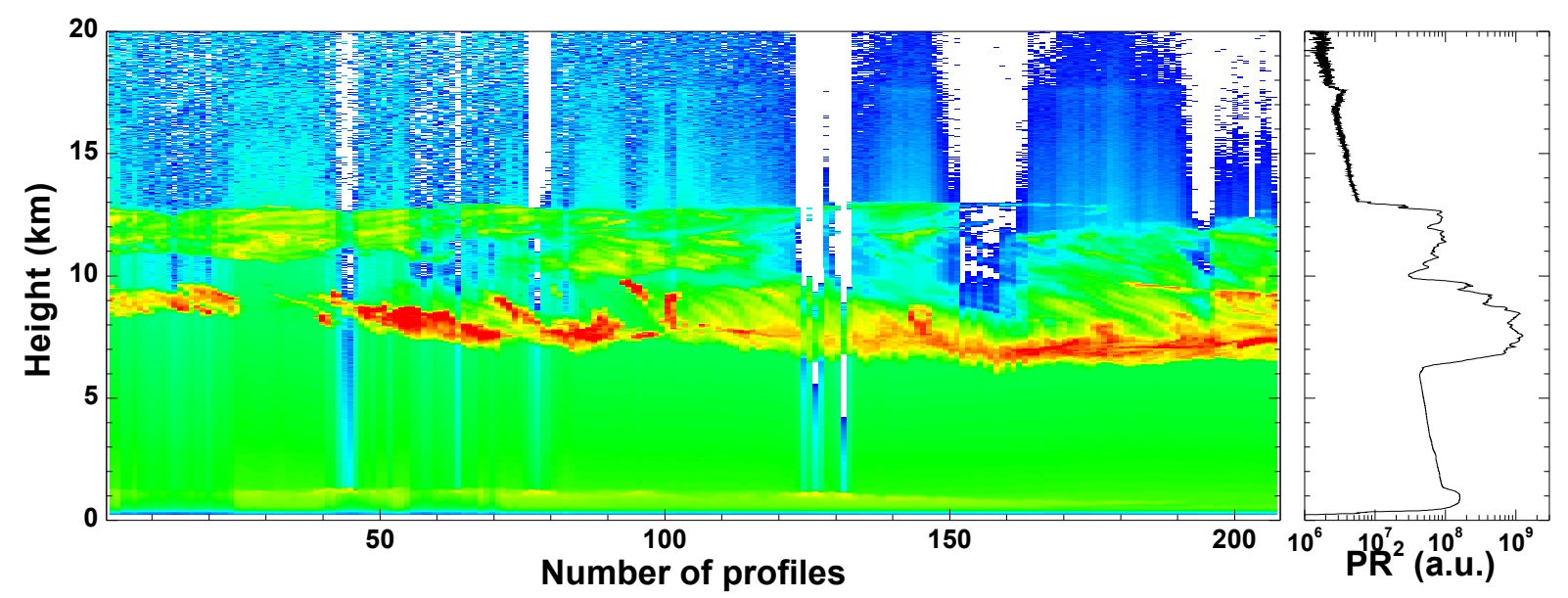

Figure 3: Time-height display (left) and average profile (right) of the range-corrected signed at $532 \mathrm{~nm}$ detected during a measurement between 1644 and 2010 UTC on 28 September 2017 with a temporal resolution of one minute.

observations being performed during daytime, reasonable signals can be obtained up to a height of $20 \mathrm{~km}$. Aerosol can be seen in the lowermost $4 \mathrm{~km}$ as well as in layers at $7,11,14,15$, and $16 \mathrm{~km}$ height. The temperature profile of a radiosonde launched at Nottingham (about $150 \mathrm{~km}$ north of Hatfield) shows the tropospause at about $10 \mathrm{~km}$ height, putting the upper aerosol layers-likely originating from pyro-cumulonimbus events in Canada several weeks earlier-well within the stratosphere.

Figure 3 presents data from the first nighttime measurement performed with LiSsI. The configuration has been the same as during the measurements presented in Figure 2. Cirrus clouds are clearly visible between 6.5 and $13.0 \mathrm{~km}$. The stratospheric aerosol layer from Figure 2 is still present between 17 and $18 \mathrm{~km}$ height.

\section{NEXT MILESTONES}

The coming milestones in developing the LiSsI facility are aligned with increasing the complexity of the optical setup. After the initial test measurements (Figure 2), we intend to perform atmospheric measurements of elastically and inelastically backscattered light at the different laser wavelength using full power. After that, the spectrometer will be integrated into the lidar receiver to allow for multispectral measurements in the atmosphere and using the gas and aerosol chambers in the laboratory.

\section{ACKNOWLEDGEMENTS}

The LiSsI facility has been funded by the University of Hertfordshire through capital investment. Boyan Tatarov is supported by a Marie SkłodowskaCurie Action Fellowship of the European Commission (CAPABLE, H2020-MSCA-IF-2015).

\section{References}

[1] Tatarov, B. and Sugimoto, N., 2005: Estimation of quartz concentration in the tropospheric mineral aerosols using combined Raman and high spectral resolution lidars, Opt. Lett. 30, 3407-3409.

[2] Müller et al., 2010: Mineral quartz concentration measurements of mixed mineral dust/urban haze pollution plumes over Korea with multiwavelength aerosol Raman-quartz lidar, Geophys. Res. Lett. 37, 2010GL044633.

[3] Tatarov et al., 2011: Lidar measurements of Raman scattering at ultraviolet wavelength from mineral dust over East Asia, Opt. Expr. 19, 1569-1581. 